\title{
New Perspectives on Observed and Simulated Antarctic Sea Ice Extent Trends Using Optimal Fingerprinting Techniques*
}

\author{
WILLIAM RICHARD HOBBS \\ Institute for Marine and Antarctic Studies, University of Tasmania, Hobart, Tasmania, and Australian Research Council \\ Centre of Excellence for Climate System Science, Sydney, New South Wales, Australia
}

NATHANIEL L. BINDOFF

Institute for Marine and Antarctic Studies, University of Tasmania, Hobart, Tasmania, and Australian Research Council Centre of Excellence for Climate System Science, Sydney, New South Wales, and CSIRO Marine Atmospheric Research, Hobart, Tasmania, and ACE CRC, Hobart, Tasmania, and CAWCR, Melbourne, Victoria, Australia

\author{
MARILYN N. RAPHAEL \\ Department of Geography, University of California, Los Angeles, Los Angeles, California
}

(Manuscript received 23 May 2014, in final form 28 October 2014)

\begin{abstract}
Using optimal fingerprinting techniques, a detection analysis is performed to determine whether observed trends in Southern Ocean sea ice extent since 1979 are outside the expected range of natural variability. Consistent with previous studies, it is found that for the seasons of maximum sea ice cover (i.e., winter and early spring), the observed trends are not outside the range of natural variability and in some West Antarctic sectors they may be partially due to tropical variability. However, when information about the spatial pattern of trends is included in the analysis, the summer and autumn trends fall outside the range of internal variability. The detectable signal is dominated by strong and opposing trends in the Ross Sea and the AmundsenBellingshausen Sea regions. In contrast to the observed pattern, an ensemble of 20 CMIP5 coupled climate models shows that a decrease in Ross Sea ice cover would be expected in response to external forcings. The simulated decreases in the Ross, Bellingshausen, and Amundsen Seas for the autumn season are significantly different from unforced internal variability at the $95 \%$ confidence level. Unlike earlier work, the authors formally show that the simulated sea ice response to external forcing is different from both the observed trends and simulated internal variability and conclude that in general the CMIP5 models do not adequately represent the forced response of the Antarctic climate system.
\end{abstract}

\section{Introduction}

Sea ice is an important indicator of polar climatic changes, because it is sensitive to both the atmosphere and ocean. Since 1979, when satellite passive microwave retrievals of sea ice concentration became possible,

\footnotetext{
* Supplemental information related to this paper is available at the Journals Online website: http://dx.doi.org/10.1175/JCLI-D-1400367.s1.

Corresponding author address: Will Hobbs, Institute for Marine and Antarctic Studies, University of Tasmania, Private Bag 129, Hobart TAS 7000, Australia.

E-mail:whobbs@utas.edu.au
}

observations show a modest increase in Antarctic sea ice cover, which is in stark contrast to the rapid decline in Arctic ice cover over the same period. These Southern Ocean trends are statistically significant in the context of variability over the observed time scale and are robust to changes in the observing system (Cavalieri et al. 1999; Parkinson and Cavalieri 2012). By contrast, most climate models driven by realistic natural and anthropogenic forcings simulate a significant decrease in Antarctic sea ice cover over the same period (Turner et al. 2013; Fig. 1), and it is not clear whether the observed changes represent an externally forced change or multidecadal natural variability. Over the same period, coupled models replicate the observed decline in Arctic sea ice cover reasonably well (Stroeve et al. 2012), which 

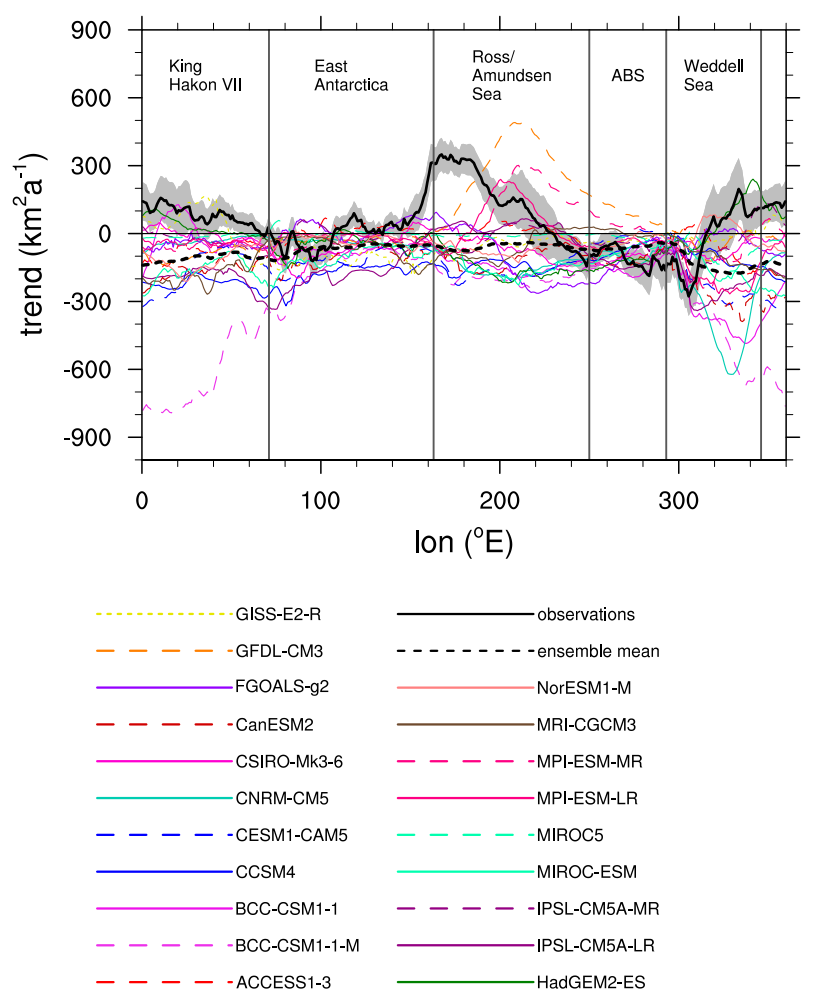

FIG. 1. Spatial pattern of 1979-2005 historical experiment trends, calculated from monthly data after removal of the seasonal cycle. Black curve shows the 1979-2005 observed equivalent, with trend standard error shown by gray shading; dashed black curve shows the multimodel ensemble mean. The spatial sectors are as defined by Raphael and Hobbs (2014).

could mean that the Antarctic system has a much weaker response to external forcings than the Arctic or that there are processes that are either deficient or missing from the coupled models' representation of sea ice, which are unique to the Antarctic climate system. Clearly, there is a need to identify whether or not observed changes in Antarctic sea ice are due to external climate forcings.

A number of recent studies have analyzed trends in total Southern Ocean sea ice extent (SIE), with respect to phase 5 of the Coupled Model Intercomparison Project (CMIP5) suite of standardized climate model experiments. These studies conclude that the observed SIE trend is within the range of the models' internal variability, and therefore the trend cannot be attributed to anthropogenic forcing (Mahlstein et al. 2013; Polvani and Smith 2013; Swart and Fyfe 2013; Zunz et al. 2013). Similarly, the simulated decrease in Antarctic SIE since 1979 is also within the range of internal variability; hence, the apparent discrepancy between models and observations does not necessarily indicate a failure in the models (Swart and Fyfe 2013).
These studies considered only the total ice cover integrated over the entire Southern Ocean (Mahlstein et al. 2013; Polvani and Smith 2013; Swart and Fyfe 2013; Zunz et al. 2013), but in fact observed Antarctic sea ice trends are spatially heterogeneous and even opposing in sign (Maksym et al. 2012), with increased ice cover in the Ross Sea and decreased cover in the AmundsenBellingshausen Seas (Fig. 1). Hence, these opposing trends partially compensate each other, and the total SIE variable masks the strong regional signals. Use of the total SIE to evaluate Antarctic sea ice changes may be valid but only with the implicit assumption that the spatial pattern of trends is merely due to natural variability, so that total SIE is a robust, relatively noise-free indicator of change. However, there is some evidence to suggest that the dipole pattern of observed sea ice change is a coherent physical response to external forcing. Holland and Kwok (2012) indicate that wind-driven sea ice transport may have a role in explaining some of the observed local trends, although it should be noted this relationship is complicated by ocean-ice-atmosphere feedbacks that relate spring and autumn sea ice trends (Holland 2014). Several studies suggest that atmospheric changes forced by multidecadal tropical Pacific and Atlantic variability could explain spatially heterogeneous changes in the Antarctic (Ding et al. 2011; Li et al. 2014; Okumura et al. 2012; Simpkins et al. 2014). It has also been suggested that freshwater forcing from melt of West Antarctic ice sheets and ice shelves (a mechanism absent from the CMIP5 models, which do not have ice sheets) could explain the regional trends. If this cold, fresh meltwater were transported by coastal currents to the Ross Sea (Bintanja et al. 2013), it could help to explain the observed increase in ice cover in that region. However, this hypothesis remains somewhat contentious and the effect is likely to be small (Swart and Fyfe 2013). Therefore, there is the possibility that the observed pattern of sea ice change may itself be a mechanistic response to changes in the Antarctic climate system. These changes may be the result of multidecadal internal variability or a response to external forcings, but that question can only be resolved by considering spatial information in a change detection analysis.

A further issue is the question of whether the CMIP5 models are adequate for detection and attribution studies of Antarctic sea ice. The use of models is necessary, both to represent long-term variability, which the instrumental record is too short to capture, and to estimate a theoretical response to external forcings for attribution purposes. Many of the CMIP5 models are known to give a generally poor representation of the Antarctic SIE climatology (Turner et al. 2013), which must diminish confidence in their utility. However, their 
representation of the mean climatology does not necessarily negate their representation of interannual variability or response to external forcings. The optimal fingerprinting techniques used in detection and attribution studies provide a sophisticated way of objectively comparing forced responses and internal variability between models and observations. Thus, in addition to their use in estimating the climate's response to forcing, optimal fingerprinting techniques may provide useful insights into model validity that are absent from more simple analyses. This also has implications for the projected decrease in Antarctic sea ice over the next century (Collins et al. 2014), since an adequate representation of late-twentieth-century changes is a necessary condition for trusting model projections.

The spatial heterogeneity of the observed trend and its possible relationship to large-scale variability make a clear case for including the spatial pattern of trends in a detection analysis, and concerns over model performance demand a careful assessment of simulated internal variability and forced response. In this study, we aim to identify whether observed Antarctic sea ice changes are detectably different from natural variability and whether the CMIP5 models adequately represent sea ice variability and response to climate forcings. To that end, we apply optimal fingerprint techniques to the regionally heterogeneous trend pattern of Antarctic SIE, combining coupled model simulations with observations.

\section{Data and methods}

\section{a. Observed data and model simulations}

The observational data were monthly Goddard passive microwave sea ice concentrations, available from the National Snow and Ice Data Center (Meier et al. 2013a). Observations at this resolution may include features within the ice pack (e.g., polynyas) that the coarse-resolution global coupled models cannot be expected to represent. For this reason, sea ice extent was chosen as a parameter (rather than, e.g., sea ice concentration or areal cover), since it does not include such features. Perhaps the most important characteristic for an observational dataset for change detection is that it is temporally consistent over the analysis period. It has been suggested that this may not be the case for Antarctic sea ice estimated using the "bootstrap" passive microwave retrieval algorithm (Eisenman et al. 2014); to alleviate the possibility of spurious observed trends we used data that were processed using the NASA team algorithm. The data were interpolated from their native $25 \mathrm{~km}^{2}$ grid onto a $0.5^{\circ}$ longitude $\times 0.25^{\circ}$ latitude grid (approximately $25 \mathrm{~km} \times 25 \mathrm{~km}$ at $60^{\circ} \mathrm{S}$ ), from which the
SIE was calculated as the total area per degree longitude bounded by the coast and the 0.15 sea ice concentration isoline. The same process was used to calculate SIE from the modeled sea ice concentrations.

We use output from two sets of experiments in the CMIP5 suite (Taylor et al. 2012). The preindustrial control runs (piControl) were run freely using a climatological solar forcing that did not change from year to year and is used in this study to represent the models' estimates of internal variability. The available control run lengths vary between models, but for this study we use only models with a control run of at least $270 \mathrm{yr}$ : that is, at least 10 nonoverlapping $27-y r$ time segments to compare with the 1979-2005 period. (Differences in the observed trends between the 1979-2005 and 1979-2013 periods are shown in Fig. S1 of the supplemental material.) To represent the externally forced climate response we use the CMIP5 historical simulations, which were run freely from a stable branch time of the control run, forced by realistic expressions of natural (solar and volcanic) and anthropogenic forcings (greenhouse gas, ozone, anthropogenic aerosols, and land-use change) from the mid-nineteenth century to 2005 . The optimal fingerprint analysis described in section $2 b$ below requires that the vector representing the forced response is free from noise due to internal variability, which is achieved by averaging multiple ensemble members of each model's historical simulation. From simple statistical theory, where standard error is defined as the standard deviation divided by the square root of the degrees of freedom, about seven ensemble members would be required to reduce the sampling error in the response pattern to $1 / e$ of the standard deviation. Unfortunately, few models have such large ensemble sets available, and so we restrict the analysis to models with historical ensemble sizes of at least three to give a balance between noise reduction in the estimated response and inclusion of a range of different models. (Sensitivity of the results to ensemble size is shown in Fig. S2 of the supplemental material.) The total set of models used is summarized in Table 1.

Many of the models suffer from "drift" (i.e., spurious long-term trends in ocean temperature because of insufficient spinup or unrealistic terms in their energy budgets), and these temperature drifts can impact model sea ice cover. To minimize these effects, for all analyses the first-order linear trend in control run sea ice was calculated for each model and removed from the historical experiment trends. Drifts were retained in the control runs however, to avoid the risk of reducing the internal variability by detrending. In practice, the magnitude of Antarctic SIE model drift is modest for all but a few models (see Table 1). 


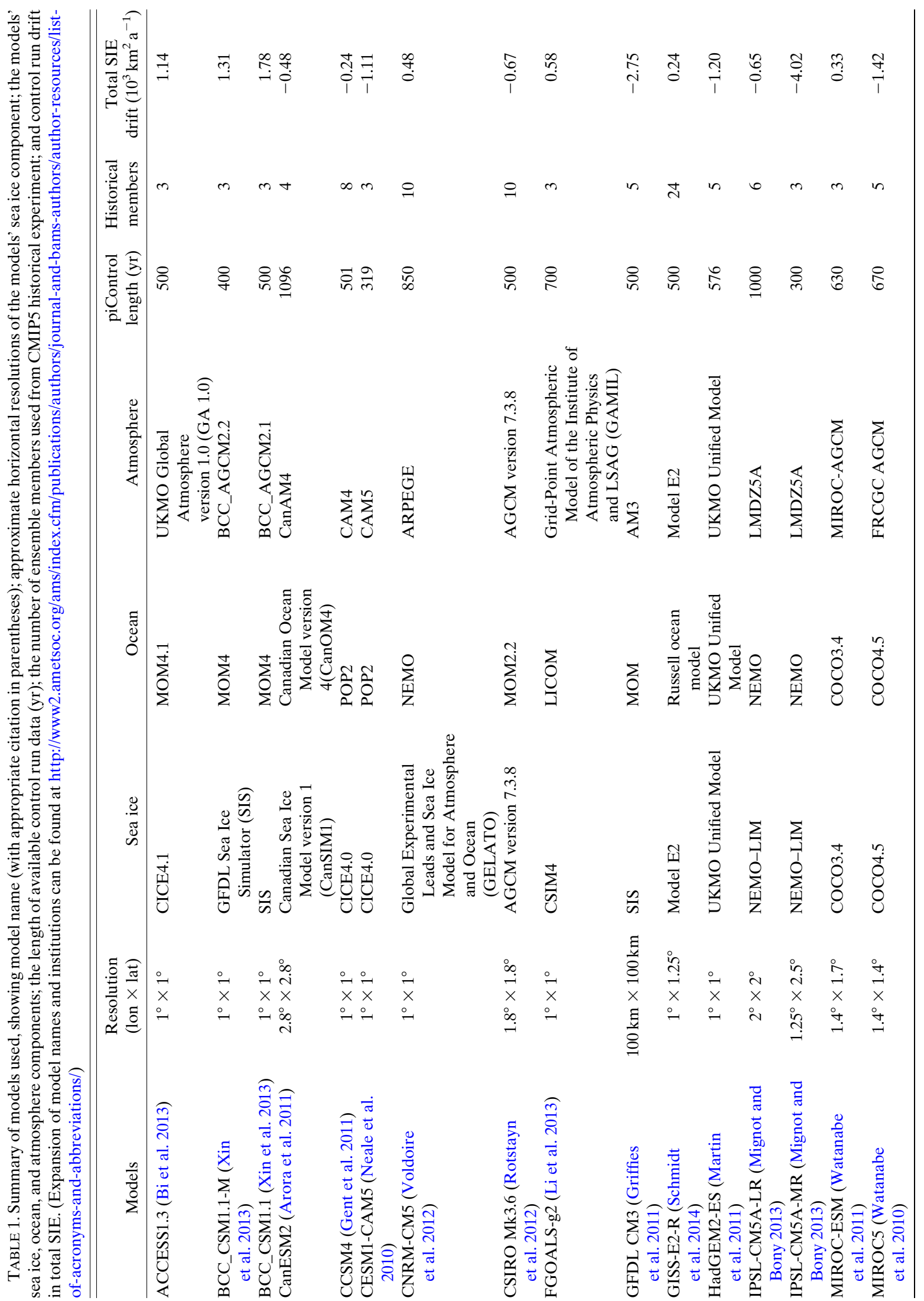




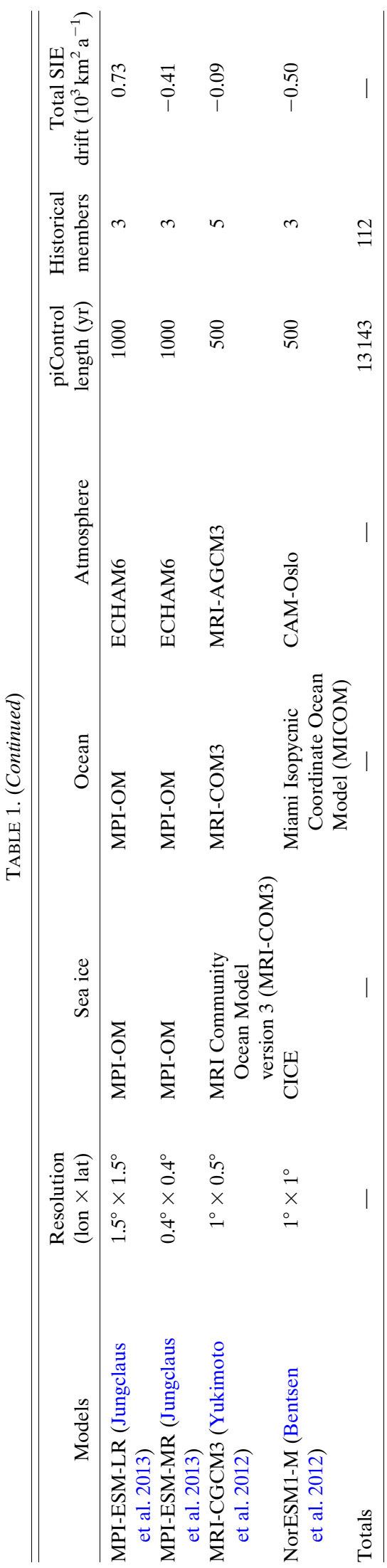

\section{b. Optimal fingerprinting}

In simple terms, optimal fingerprinting methods use a linear regression to compare a vector of observed change (in this case, observed Antarctic SIE as a function of longitude), with an estimate of how that same metric is expected to change under some external climate forcing, usually estimated using model experiments. This takes the form OBS $=\beta \mathbf{R E S P}+\mathbf{u}$, where OBS is the vector of observed change, RESP is the vector of theoretical climate response, $\beta$ is a scaling coefficient that relates OBS and RESP, and $\mathbf{u}$ is the vector of residuals. Thus, if $\beta=1$ then the models and observations have the same amplitude of response, if $\beta>1$ then the observed change has been greater than would be expected from the model response, and if $\beta<1$ then the observed change has been less than the model response. The challenge therefore is to estimate $\beta$, given that for almost all observations the response signal is small compared to the climate system's noise (i.e., internal variability). To overcome this, an optimization is used whereby the vectors OBS and RESP are divided by the noise covariance matrix $\mathbf{C}_{N}$, which is the covariance matrix of the estimated internal variability and thus contains information about the pattern and magnitude of internal variability. This transformation improves the signal-to-noise ratio by weighting the analysis away from modes with high internal variability.

The optimal fingerprint method used here is similar to that detailed in Allen and Tett (1999), and has been applied to an analysis of Arctic sea ice changes (Min et al. 2008). We used the 1979-2005 observed SIE extent trend pattern on a coarse $30^{\circ}$ longitude grid as the observation vector OBS. This spatial smoothing ensures that small-scale features, which the models cannot replicate, are not included in the analysis. The response pattern vector RESP was the ensemble-mean historical simulation 1979-2005 SIE trend for each model. The noise covariance matrix was estimated from each model's control run. The control runs are generally not sufficiently long to compute an invertible covariance matrix; even when they are, sensitivity to small values typically makes the actual inversion of the noise covariance matrix ill conditioned. Instead, empirical orthogonal functions (EOFs) were calculated for the control runs. Each EOF was divided by the square root of its eigenvalue, and the response pattern RESP and observations OBS were projected onto the resultant pattern to obtain optimal fingerprints; these optimized fingerprints were used to estimate the scaling factors $\beta$, using ordinary least squares regression. This projection has the dual purpose of reducing the dimensions of the detection vectors, and provides a Moore-Penrose pseudoinverse 
estimate of $\mathbf{C}_{N}^{-1}$. For the shortest control runs, there was a maximum of 10 EOFs nonoverlapping, 27-yr trends, and this limit of 10 was applied to all models. The results are sensitive to the number of EOFs retained, with the risk of a false detection generally increasing as more EOFs are retained and the regression becomes overfitted. To objectively ascertain the appropriate number of EOFs to include in the optimal fingerprints, we applied a consistency check to each model and season as outlined in Ribes et al. (2013). Residuals (u) were calculated by subtracting the response pattern multiplied by the estimated $\beta$ from the observations. In this linear "response plus noise" decomposition, u represents the internal variability (i.e., noise), so it should be consistent with the model control runs: that is, $\mathbf{u} \mathbf{C}_{N}^{-1} \mathbf{u}^{\mathrm{T}}=1$. If $\mathbf{u C}_{N}^{-1} \mathbf{u}^{\mathrm{T}}$ is statistically different from unity, then the estimate of $\beta$ must explain too much or too little of the observed variance and the regression is not valid. As per Ribes et al. (2013), we use an $F$ distribution to determine whether $\mathbf{u C}_{N}^{-1} \mathbf{u}^{\mathrm{T}}=1$ is within the $99 \%$ confidence bounds. For each season and model, the truncation level was taken as the maximum number of retained EOFs that passed the consistency test.

To estimate the uncertainty in each model's scaling factor, the control runs were split into as many pseudoobservations (i.e., 27-yr trend patterns) as allowed by the control run length. The optimal fingerprint analysis was repeated for each pseudo-observation separately, and the largest value of $\beta$ among the pseudo-observations gives an estimate of the maximum apparent response that might be expected from internal variability alone. Since the model control runs are of differing lengths there is a possibility that models with fewer pseudo-observations may have an underestimate of the true range of uncertainty, although in practice we find no strong relationship between control run length and uncertainty estimates. When the total range of $\beta$, including the forced response and range of natural variability does not include zero, the observed trend cannot be explained by internal variability alone and a forced response is said to be detectable.

A number of points made in Allen and Tett (1999) may be helpful in interpreting $\beta$ and its range. First, the null hypothesis that there is no forced response in the observations (i.e., $\beta=0$ ) can be rejected if scaling factor plus the range of uncertainty does not include 0 (i.e., a forced response is "detectable"). Similarly, the hypothesis that the model-predicted response is correct (i.e., $\beta=1$ ) can be rejected if the scaling factor range does not include 1 . This case may stem from an underrepresentation of internal variability, an incorrect physical response to forcing, or a combination of both. For the purpose of this article, we will define models that have a scaling factor range that does not include 1 as "questionable."

\section{Results}

\section{a. Influence of teleconnected decadal variability}

An important issue in change detection, where the observations cover a relatively short time period, is the question of whether trends are due to an aliasing of variability at multidecadal and longer time scales. In theory, multicentury control simulations should include these long-term modes of internal variability, but in practice it is very difficult to ascertain whether the models adequately represent variability at long time scales; this is especially true for Antarctic sea ice, where observations are largely restricted to just three decades of passive microwave data. Observed Southern Ocean sea ice trends have significant decadal differences, implying that some of the observed trends may be an alias of multidecadal variability (Fan et al. 2014; Simpkins et al. 2013). Previous studies have shown that atmospheric teleconnections with the tropical Pacific (Ding et al. 2014; Okumura et al. 2012; Schneider et al. 2012) and tropical Atlantic (Li et al. 2014; Simpkins et al. 2014) are related to multidecadal Antarctic SIE variability. Analysis related to the pause in global surface temperature change over the last decade suggests that in particular multidecadal tropical Pacific variability may be underestimated in the CMIP5 models (England et al. 2014); hence, it is worthwhile to verify how sensitive the observed trends are to multidecadal teleconnections that cannot be easily validated in the models. We therefore use observed multidecadal indices to test, independently of the models, whether the observed trends could be an alias of multidecadal natural variability.

We use the Pacific decadal oscillation (PDO) index (Mantua et al. 1997) to represent multidecadal Pacific variability (obtained from the University of Washington Joint Institute for the Study of the Atmosphere and Ocean: http://jisao.washington.edu/pdo/) and the Atlantic multidecadal oscillation (AMO) index (Enfield et al. 2001) to represent Atlantic variability (obtained from the NOAA/Earth System Research Laboratory: http://www. esrl.noaa.gov/psd/data/timeseries/AMO/). The 1979-2013 indices were detrended for each season, as was the SIE data for the same period, and the regression coefficients were calculated for each index separately. These coefficients were multiplied by the indices (including trend), and the resulting estimated signals were removed from the SIE data. The SIE trends were then recalculated, excluding the AMO or PDO signal (Fig. 2).

The AMO (Fig. 2, blue line) seems to have little influence on the trends during any season. The PDO 

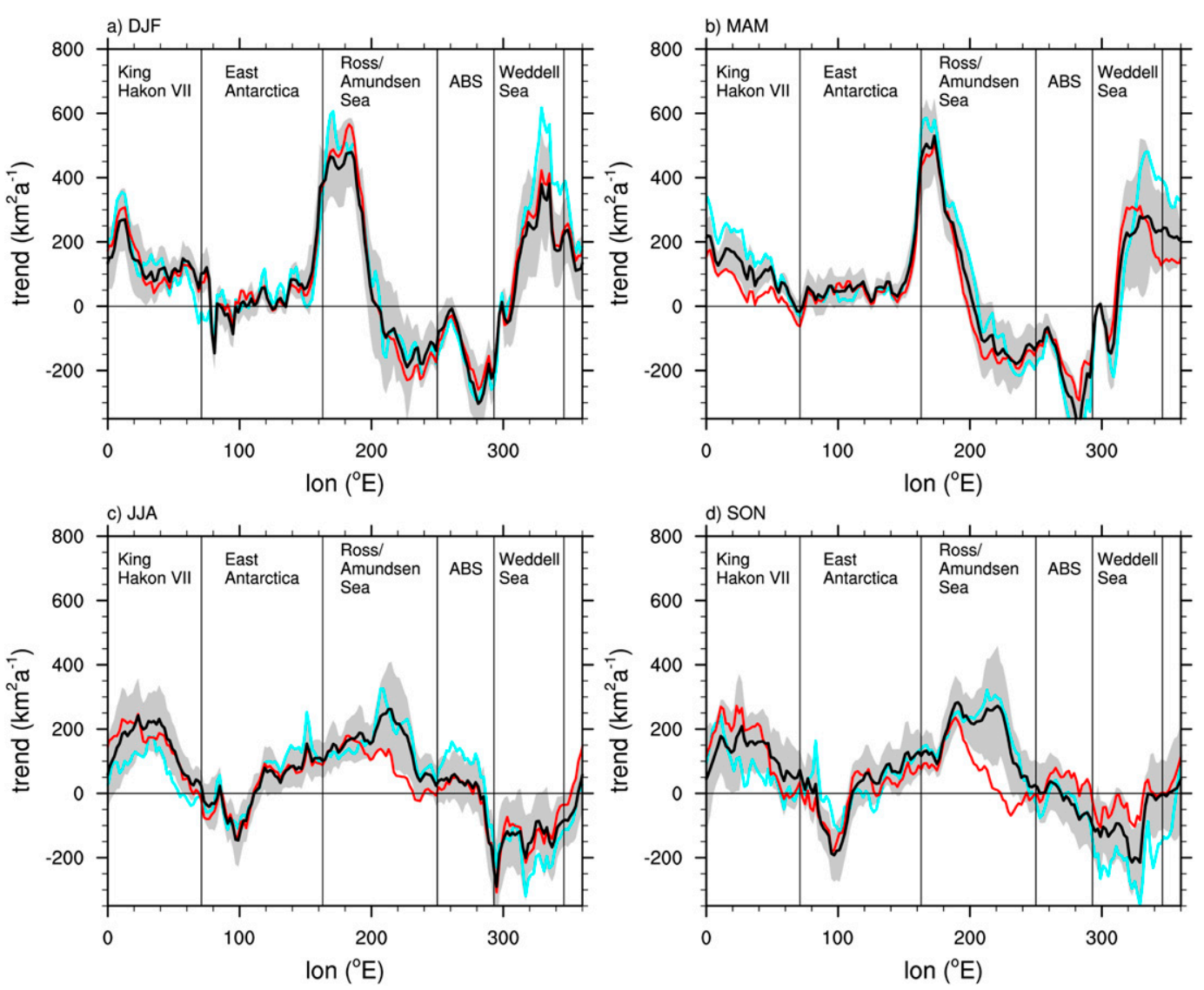

FIG. 2. (a)-(d) Observed 1979-2013 trends (black), with standard error (gray), after removal of the PDO signal (red), and after removal of the AMO (blue) by season.

(Fig. 2, red line) has even less influence during summer and autumn (Figs. 2a and 2b), but in SeptemberNovember (SON) it explains some of the trends in the West Antarctic sectors (i.e., the Ross, AmundsenBellingshausen, and Weddell Seas). This result is consistent with recent studies showing that some of the observed winter and spring SST and sea ice changes in the Ross, Amundsen, and Bellingshausen Seas may be partly due to tropical Pacific multidecadal variability (Ding et al. 2011; Schneider et al. 2012). We also note that the timing of the PDO response is physically plausible, given that the tropical Pacific SH teleconnection peaks in SON when seasonal atmospheric vorticity gradients allow a wave train to propagate from the tropical Pacific to the West Antarctic region (Jin and Kirtman 2010). An important caveat to this result is that, with just three decades of data, the true multidecadal teleconnection may be underrepresented. A complete quantification of this effect, while an important and interesting topic in its own right, would require much more detailed analysis than is appropriate here.

The key point in the context of this analysis is that, based on an admittedly short time period, tropical teleconnections may have had an influence on winter and spring trends, consistent with recent studies (Li et al. 2014; Simpkins et al. 2014). However, there is no evidence to suggest that summer and fall trends are largely due to multidecadal variability (Figs. 2a,b). Having ascertained that the observed trends cannot be readily explained by known multidecadal modes, in the next section we use optimal fingerprinting to assess whether the observed trends could be explained by internal variability alone. (Note that for the remainder of this paper the observations have included the AMO and PDO signals.)

\section{b. Optimal fingerprint results}

Figure 3 shows the results of the optimal fingerprint analysis applied to the 1979-2005 Antarctic SIE trend, using the model "historical" simulations. The reader will notice that some models do not have a result for certain seasons; in these cases, the regression model failed the consistency check described in section $2 \mathrm{~b}$ at all levels of EOF truncation. For the seasons of maximum sea ice cover, June-August (JJA) and SON (Figs. $3 \mathrm{c}$ and $3 \mathrm{~d}$ ), the results clearly show that the observed trend is within the 

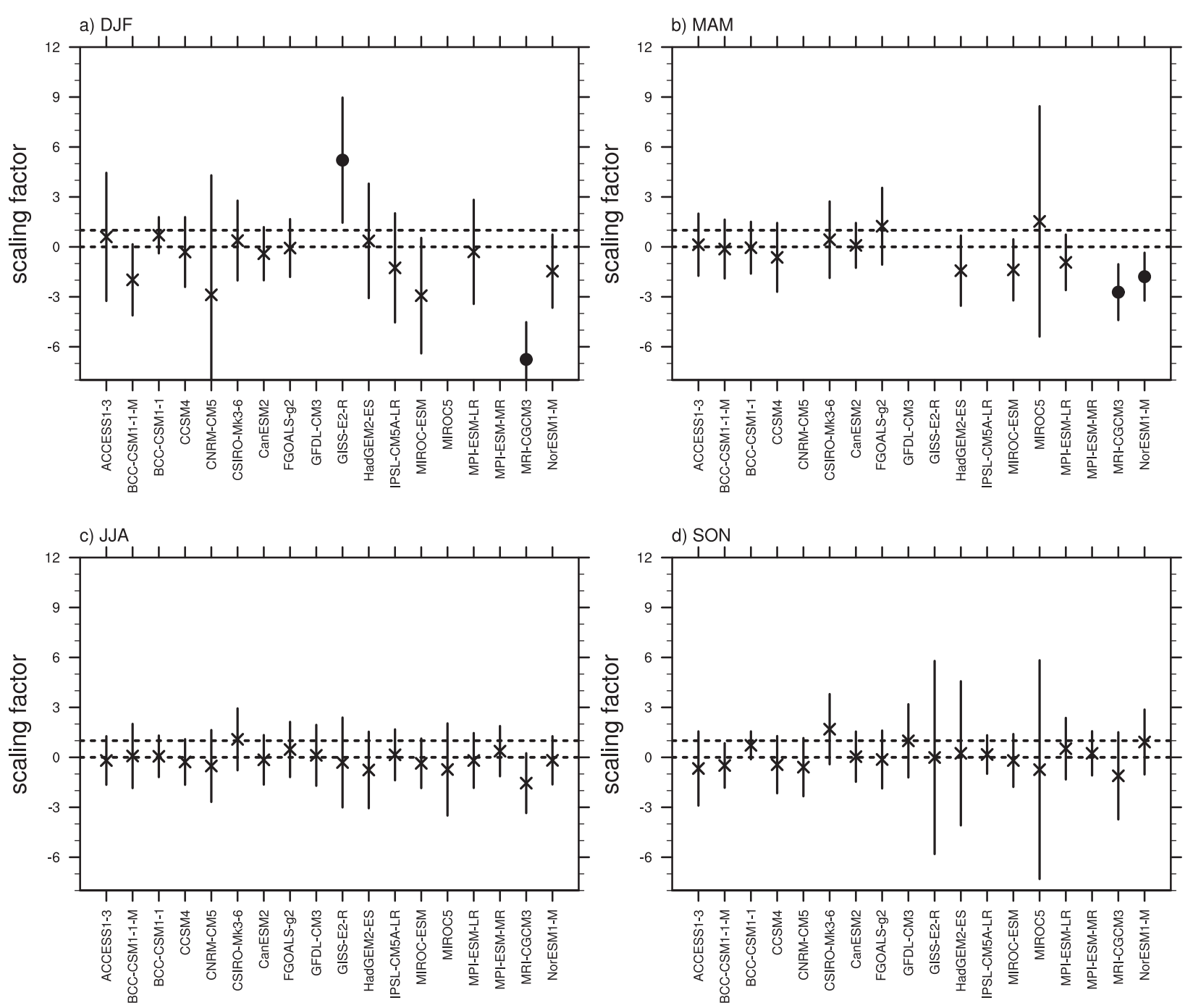

FIG. 3. (a)-(d) Optimal fingerprint analysis scaling factors (i.e., $\beta$ values) by season. Markers show the scaling factor between the response pattern (i.e., ensemble average historical simulation 1979-2005 SIE trend for each model) and the observed SIE over the same period. [In (b) IPSL-CM5A-MR has a $\beta=-14.1$.] Vertical lines show the uncertainty range, which is taken as the largest absolute $\beta$ value found in each model's control simulation. Closed circles indicate models where the observed trend is detectable, and crosses are used otherwise.

range of internal variability, since all the models that are not questionable have a range of $\beta$ that includes 0 (where we recall from section $2 \mathrm{~b}$ that questionable models have a range of $\beta$ values that does not include 1 ). During summer and autumn, the results are less reliable (Figs. 3a,b). For autumn [March-May (MAM); Fig. 3b], 12 of the 20 models do not capture the observed trend at all, since they either fail the consistency check or have a questionable range of response. There is a wide spread of responses among the remaining 10 models, with $-0.63 \geq \beta \geq 1.53$, and an average $\beta=0.33$. Results are similar for summer [December-February (DJF); Fig. 3a], with eight models giving questionable results and a wide range of $\beta$ values among the remainder. Inconsistencies among the models, in both their forced responses and their range of natural variability, render the summer and autumn results difficult to interpret.

For all seasons, those models with a questionable sea ice response have negative or extremely low scaling factors, but there is no apparent relationship between the range of uncertainty and whether a model's results are questionable. This indicates that the spread of responses is due to disagreement among the "best fit" scaling factors (calculated from the forced model experiments) rather than from the internal variability ranges, and it may be the case that the models represent internal variability adequately but not the forced response. It is then useful to reframe the detection problem in a way that is independent of the models' forced responses. To do this, we pose the question of whether 
the magnitude and spatial pattern of the observed SIE change occurs within the models' range of internal variability. Previous studies have posed a similar question, but used total SIE rather than including spatial information (Mahlstein et al. 2013; Polvani and Smith 2013). We set the response pattern RESP to be the observed trend; the linear trend was calculated for each longitude, and the time evolution of SIE resulting from the linear trend only was used as the response (see Fig. 4b). In simple terms, this approach tests whether the observed changes are outside the expected range of the control climate, rather than whether the observed changes are consistent with the models' responses to historical forcings. Since this detection analysis was not constrained by the 2005 ending of the historical simulations, the analysis was extended to the 1979-2013 period to include the maximum length of observations currently available (i.e., $35 \mathrm{yr}$ ), restricting the analysis to the 18 models with a control run length of at least $350 \mathrm{yr}$ (i.e., 10 nonoverlapping 35 -yr periods). To enable a consistency check between the residuals and the noise covariance matrices, the observation pattern OBS was the temporal evolution of the SIE as a function of longitude, rather than the trend: that is, OBS(time, longitude) (see Fig. 4a). Therefore, the time series residuals after trend removal can be directly compared with the simulated noise covariance matrices of control run 35-yr time segments. Since the scaling factors were estimated after projection onto the model's EOFs, they are generally a little less than 1 and vary between each model.

For the seasons of maximum ice cover, the models again generally show that the observed trend is within the range of internal variability. For JJA (Fig. 5c), 65\% of the models indicate that the observed trends are within the range of internal variability (i.e., not detectable), compared to $10 \%$ indicating that the trend is detectable. For SON (Fig. 5d), $45 \%$ of the models indicate that the trend is not detectably different from internal variability, compared to $20 \%$ indicating that the trend is detectable. (The remaining models in both seasons either failed the consistency check or were questionable.) Despite some disagreement among the models and a relatively high failure rate, on balance we cannot confidently reject the null hypothesis that trends in the winter and spring seasons are simply due to internal variability. The situation is different for summer and autumn (Figs. 5a and 5b). For both seasons, $70 \%$ of the models indicate that the observed trend is outside the range of internal variability (i.e., their range of $\beta$ values does not include 0 ), compared to $15 \%$ for which the trend is within internal variability. Taken as an ensemble across all the models, only $2.8 \%$ of the 11894 control run

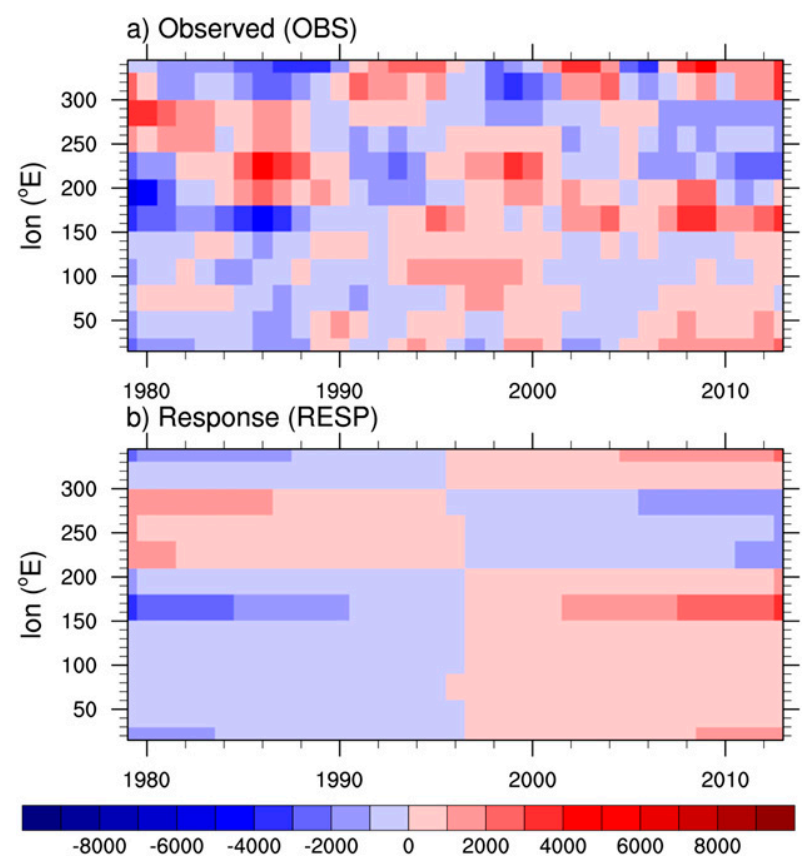

FIG. 4. Example detection and response pattern used for optimal fingerprint analysis based on observed trend. (a) Detection pattern (OBS) is the MAM 1979-2013 observed SIE anomaly $\left(\mathrm{km}^{2}\right)$, mapped onto a coarse $30^{\circ}$ longitude grid and temporally smoothed by a 3 -yr moving average; thus, the OBS pattern includes the linear trend and its residuals. (b) The response pattern is the time evolution of SIE on the same coarse grid as OBS but resulting from the linear trend only.

DJF pseudo-observations have a $\beta$ value that is greater than observed, and for MAM this is $0.26 \%$.

This is a strong indication that the observed trends are outside the range of internal variability for these seasons and may thus represent a forced response. There are three possible explanations for why the observed trend pattern is outside the range of control run variability for most models, in DJF and MAM:

1) The analysis has a selection bias that stems from using the observed trends in place of a modeled response.

2) The observed trends represent a forced response that is not adequately represented by the CMIP5 models.

3) The observed Ross Sea/Amundsen-Bellingshausen Sea (ABS) trends represent a mode of internal variability that is not adequately represented by the model control runs.

In the next section (section 3c), we discuss the risk of selection bias in our methodology (i.e., the first hypothesis). In section 3d, we explore the second hypothesis by examining the ensemble of simulated forced responses and show that taken as an ensemble the models indicate a reduction in SIE in all sectors that is significantly different from the control run. In section $3 \mathrm{e}$, 

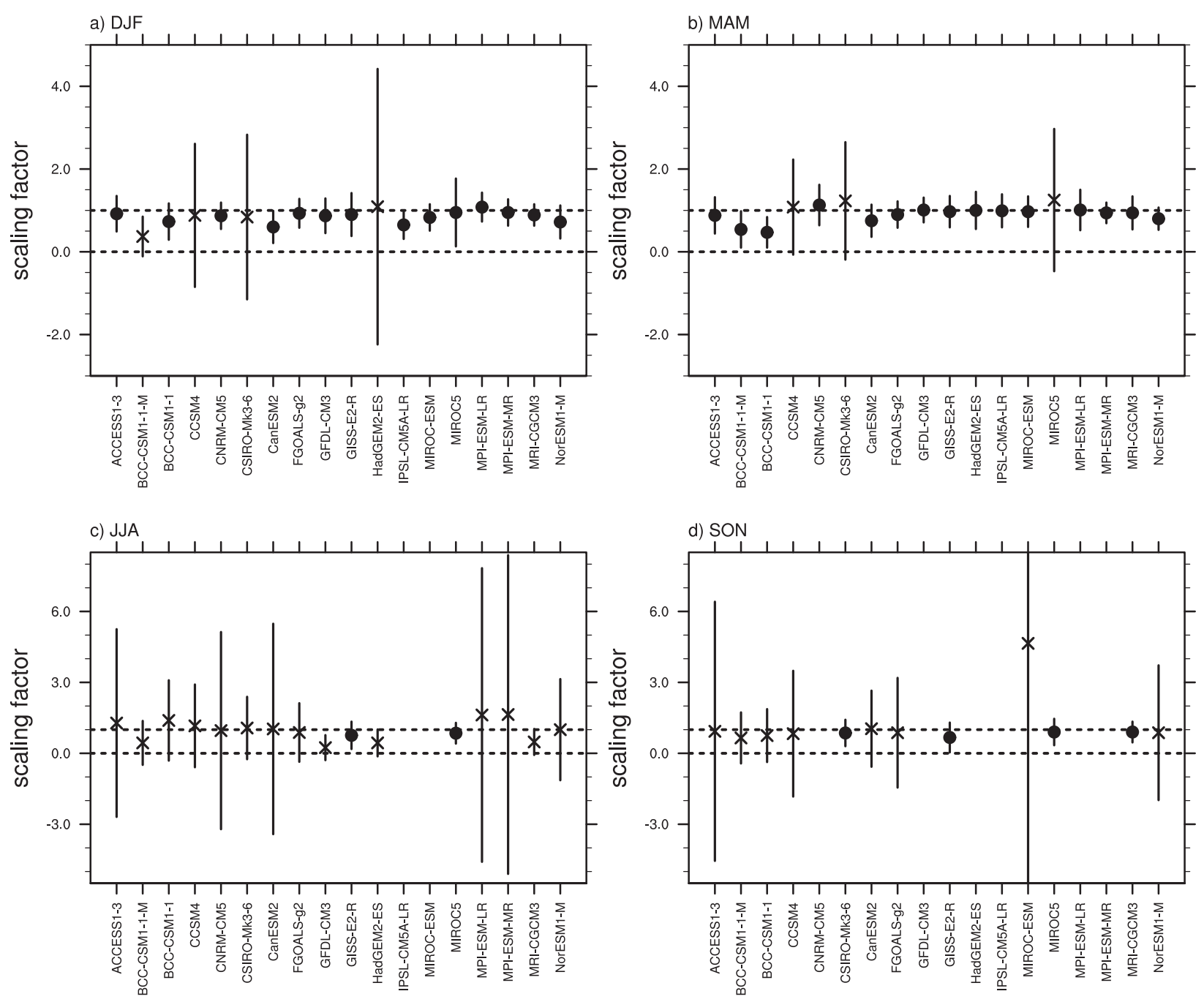

FIG. 5. As in Fig. 3, but for a response pattern based on the observed 1979-2013 trend (Fig. 4b). Vertical lines show the uncertainty range estimated by regressing the response pattern against 35-yr SIE segments from each model's control simulation.

we consider the third hypothesis by exploring the leading modes of internal variability in the models and demonstrate that the modes that project most strongly onto the observed trend pattern are reasonably well represented in the models.

\section{c. Selection bias}

Selection bias is a particular methodological concern with this approach, since there is a risk that the models are being tested solely on their ability to exactly replicate a single realization of the "true" climate that includes natural variability. It is important to emphasize a number of points. First, we did not test for agreement between the forced response pattern and the observations (i.e., the best-fit $\beta$ value), as is the case in a conventional optimal fingerprint study, but merely whether the observed trend was outside the range of responses in a plausible simulated climate without external forcing (indicated by the complete range of $\beta$ values). Second, only the large-scale features of variability are compared between the observations and models. All the data are spatially smoothed onto a very coarse $30^{\circ}$ longitudinal grid, and a 3 -yr running mean is applied to the model and observation data, so that finescale aspects of the sea ice processes that the models could not be expected to reproduce are eliminated. Furthermore, the transformation of the observations using the models' EOFs ensures that the response pattern is projected onto the modes of variability of the preindustrial simulations. Finally, the consistency check helps ensure that the removal of the observed trend from the observations has not reduced the internal variability (i.e., the noise) to a level significantly less than each model's representation of internal variability: that is, the trend is not an overfitted response estimator. 

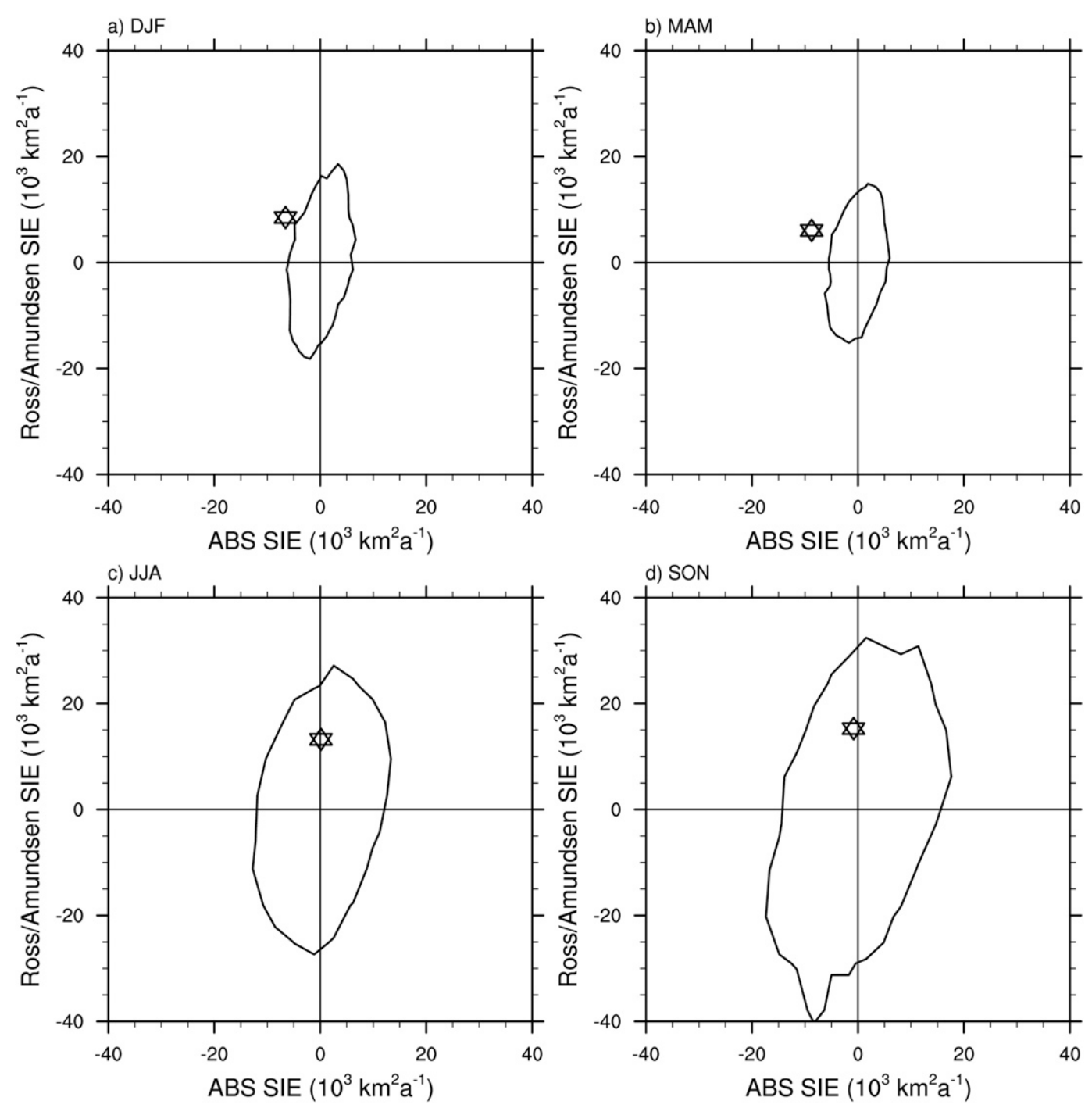

FIG. 6. Bivariate distribution of 35-yr control simulation trends from all 20 models in the Ross-Amundsen Sea ( $y$ axis) and ABS ( $x$ axis) sectors. The black curves show the $99 \%$ confidence bounds of the distribution. Markers show the observed 1979-2013 trends.

Although this treatment mitigates the chance of a false detection because of selection bias, there remains a theoretical risk since the response pattern we have used is not independent of the observations, but this choice of pattern can be justified by physical arguments. The dominant spatial feature of the observed trend pattern is the large increase in Ross-Amundsen SIE and large decrease in the Amundsen-Bellingshausen Sea sector. This is clearly demonstrated in Fig. 6, which shows the bivariate distribution of 35 -yr control run trends in the Ross-Amundsen Sea and ABS sectors. For all seasons, the preindustrial control models favor a weak positive covariance between the two sectors on multidecadal time scales, and so it is the opposing trends that bring the observed pattern outside the range of simulated internal variability in DJF and MAM. It is not so much the magnitude of the observed trends that differentiates them from internal variability but their opposing sign. This gives further support for the importance of including spatial information in the analysis. During winter and spring (Figs. 6c and 6d), the observed trend is well within the distribution and is not outside the range of internal variability. Similar bivariate distributions were calculated for all other possible sector pairings (not shown), but in all other cases the observed correlation is within the control run distributions.

If the opposing trends in the Ross-Amundsen Sea and ABS sectors are physically unrelated then of course there is a selection bias in our analysis, since we would be basing our detection on the replication of a randomly 

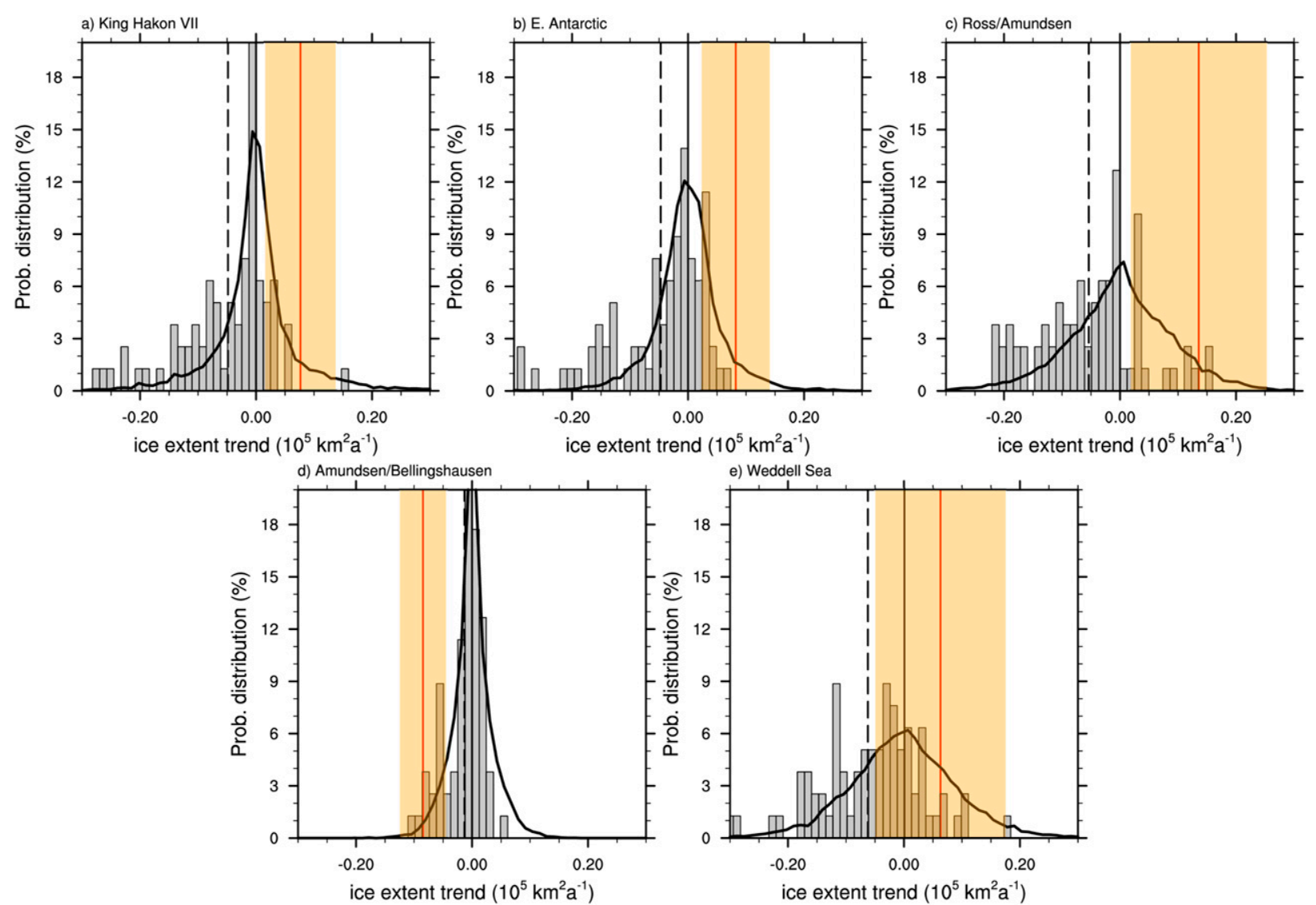

FIG. 7. (a)-(e) Distribution of 1979-2005 MAM trends by sector. The black curve is from the control simulations, bars are the historical simulations, the dashed vertical line is the historical ensemble mean, and the red vertical line is the observed trend with orange statistical uncertainty.

occurring regional pattern. Several papers suggest that this may be the case (Holland 2014; Simpkins et al. 2013), but several others show sound physical evidence that negative covariance between these sectors is a coherent physical mode of Southern Ocean SIE, for both trends (Holland and Kwok 2012) and interannual variability (Hosking et al. 2013; O'Kane et al. 2013; Yuan 2004; Yuan and Martinson 2001). In light of this, and in order to have confidence that we have genuinely identified a detectable trend in Antarctic SIE, it is necessary to test whether the pattern of observed opposing SIE trends is contained within the preindustrial control representation of internal variability. Further analysis of the models' control runs is presented in section $3 \mathrm{~d}$ in support of the detection results. In the following section, we further explore the models' representations of forced response.

\section{d. Model representations of forced response}

Here, we examine the second hypothesis presented in section $3 b$ : that is, the observed trends represent a forced response that is not adequately represented by the CMIP5 models. In practice, rejecting this hypothesis requires a complete physical understanding of the observed trends that is beyond the scope of this work and indeed is the subject of much ongoing research. However, we can explore whether the models in fact show a significant response or whether the SIE changes under the historical forcing scenario could be explained by internal variability alone. We focus on the autumn season (i.e., MAM), which shows evidence of a detectable observed signal and, as the period of ice growth, is physically important in setting the total duration of sea ice cover (Stammerjohn et al. 2008).

Figure 7 shows the distributions of the control and historical experiment MAM 27-yr SIE trends for all sectors. (To avoid biasing the results toward a single model, no more than five members were used from any individual model.) The forced response indicated by the historical simulations is generally within the range of control run variability for any individual model (Fig. 7; discussed further below). However, as has been noted there is a tendency among the multimodel ensemble toward a decrease in sea ice cover, whereas if there were no forced SIE response at all then the ensemble of historical 
simulation trends would be distributed about zero. The historical simulation ensemble mean is negative in all sectors, whereas the observed trend is only negative in the ABS region. For the other sectors, as well as opposing the historical ensemble-mean trend, the observed trends are greater than the 90th percentile of the historical simulation distribution, although it should be noted that the observed SIE trends are statistically significant only in the Ross-Amundsen Sea and ABS sectors.

We applied a two-tailed Student's $t$ test to determine whether the ensemble mean of historical simulation trends is significantly different from the mean of the control runs. The multimodel control run distribution contains 514 nonoverlapping 27-yr trends but, because of temporal autocorrelation and similarities between the models (Knutti et al. 2013), this number overstates the true degrees of freedom. The true independent sample sizes were estimated using an autoregressive approach (Zwiers and von Storch 1995), giving 158 degrees of freedom for each sector. A total of 79 historical simulation members were included in the distribution but again they could not be assumed to be independent, because of similarities among the different models and multiple ensemble members from single models. To estimate the true degrees of freedom, an equivalent sample size was estimated using the same autoregressive technique, for 10000 randomly generated permutations of the historical ensemble; the smallest number degrees of freedom for these permutations was 23 and this number was used for the $t$ tests. Using these conservative estimates for the true degrees of freedom, for all sectors we could reject at the $95 \%$ confidence level the null hypothesis that the historical forced response is no different from the control run, suggesting that the ensemble-mean historical simulations significantly reduce Antarctic SIE in response to external forcings (i.e., anthropogenic greenhouse gasses, ozone depletion, and aerosols, as well as natural volcanic and solar variability).

This analysis indicates that, while the magnitude of simulated response is too small over the relatively short period of satellite observations to be distinguished from internal variability for any individual model, there is in fact a forced decrease in SIE in all Antarctic regions when the multimodel set is analyzed. This result is consistent with the second hypothesis in section $3 \mathrm{~b}$ : that is, the observed trends represent a forced response that is not adequately represented by the CMIP5 models.

\section{e. Model representations of internal variability}

The third hypothesis in section $3 \mathrm{~b}$ is that the observed Ross-Amundsen-Bellingshausen Sea trends represent a mode of internal variability that is not adequately represented by the model control runs, and we explore

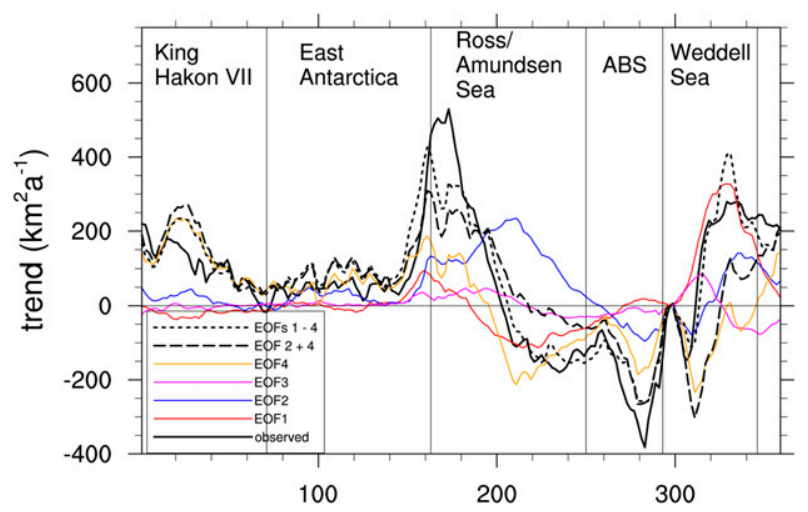

FIG. 8. The 1979-2013 MAM observed trends reconstructed from EOF time series. The observations were detrended and spatially smoothed using a $2^{\circ}$ longitude average before calculating the four leading EOFs. Time series were calculated by projecting the EOF patterns onto the observations (including the trend). Linear trends in the EOF time series were used to reconstruct the trend explained by each EOF. The dashed black line is the sum of the second and fourth EOF reconstructed trends, the dotted black line is the sum of all four reconstructed trends, and the solid black line is the observed trend.

that hypothesis here. This requires an analysis of covariance between the different sectors, and EOFs provide arguably the most convenient way of comparing the observed modes with the models. The observed data were decomposed into their leading EOFs, having first separated the data into seasons; note that linear trends were removed from the data before calculating the EOFs. To identify which modes are important in explaining the observed MAM trends, eigenvalue time series were calculated by projecting each EOF onto the observations (now including trends), and each EOF's contribution to the observed SIE trend pattern was estimated from the linear trend of each eigenvalue time series (Fig. 8). A total of 10 EOFs were calculated, and it was found that the observed trend is well represented by the sum of the four leading EOFs. In the Ross, Amundsen, and Bellingshausen Sea sectors, where the observed trends are statistically significant, the pattern is mostly due to the combination of the second and fourth EOFs. (The first EOF mainly explains variability in the Ross and Weddell Seas, and the third EOF explains very little of the trend in any sector.) To some extent, this analysis also has a bearing on the assessment of selection bias laid out in section 3b, where it was shown that the risk of selection bias rests on the question of whether the observed trends in the Ross-Amundsen Sea and ABS sectors are physically related. That the Ross-AmundsenBellingshausen Sea trends project so well onto modes of interannual variability is an indication that their opposing trends are due to a coherent, interrelated change and are not completely independent. This result diminishes 

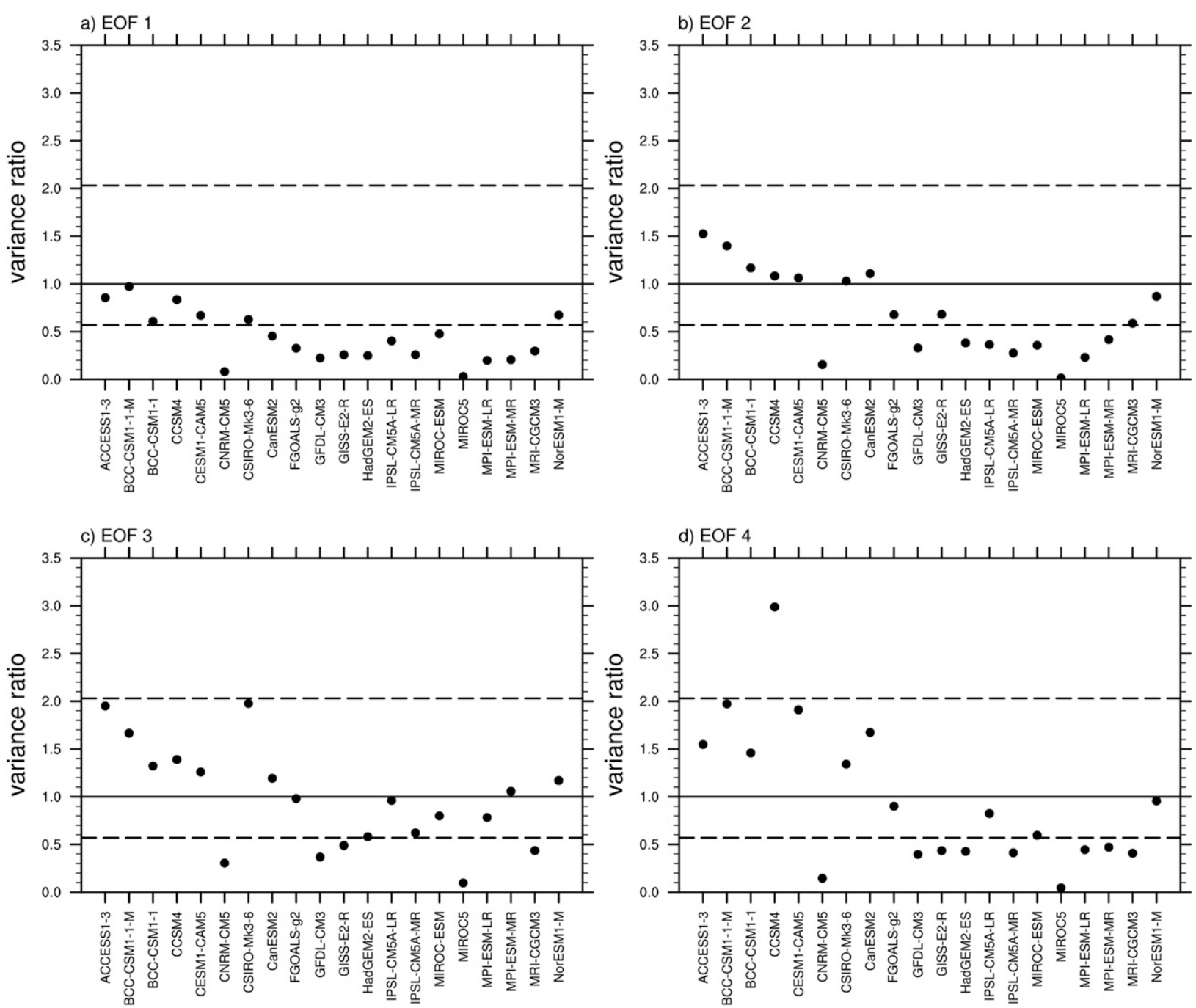

FIG. 9. (a)-(d) Ratio of model-to-observation EOF time series variance, for MAM. The time series were generated by projected the four leading observed EOF patterns onto the final $300 \mathrm{yr}$ of each model's control simulation SIE. Horizontal dashed lines show the $90 \%$ confidence bounds estimated from the $F$ distribution with 17 degrees of freedom for the observations and 75 degrees of freedom for the models. [Model degrees of freedom were estimated using Zwiers and von Storch (1995)].

the chance that the detectable trend signal is merely because of selection bias in the choice of response pattern.

Having identified the modes that are most important for the observed MAM trends, we now examine whether they are adequately represented in the models. The leading four observed EOFs were projected onto the MAM control simulations to generate projection time series for each model. This approach was taken rather than calculating EOFs for the individual models since there is no guarantee that the models' EOFs spatially match the observations, particularly for the third and fourth EOFs, which by North et al. (1982) are not statistically separable. Since the variance may have a dependence on the time series length and the models have control runs of different lengths, only the final $300 \mathrm{yr}$ were used from each control run.

The variances of each model's time series are shown in Fig. 9, as a ratio of the observed projection time series for each EOF. For all models, the leading EOF has less variance than observed, indicating that it is underrepresented in the models. However, as shown in Fig. 8 this EOF does not strongly project onto the observed trend pattern. EOFs 2-4 have ranges of variances that straddle the observed modes, and for most models the variance ratios are within the $90 \%$ confidence interval of the $F$ distribution, indicating that they have a reasonable representation of those EOFs. The second EOF (Fig. 9b) has an average variance ratio of 0.7 (i.e., the multimodel average variance is weaker than observed). The fourth 
EOF has a wider range of variances, with variances up to 3 times higher than observed and a multimodel average of 1.0 .

In summary, we have shown that the observed MAM trend projects principally onto the second and fourth EOFs of SIE variability for the same season. The strength of the projection onto these interannual modes indicates that the trends in the Ross-Amundsen-Bellingshausen Seas may be due to a coherent mode of variability, rather than occurring as unrelated events. The models exhibit a range of control run variabilities projected onto the observed EOFs, from extremely low to extremely high values. The exception is the leading EOF, which has consistently lower variance across the models than is observed. However, this mode does not project strongly onto the observed trend pattern, and it is unclear what influence this might have on the detection results. In the context of the detection analysis in section $3 \mathrm{~b}$, we proposed the hypothesis that the observed MAM trends were outside the range of internal variability, simply because the estimate of internal variability was inadequate (third hypothesis). The results in this section indicate that this is likely not the case, and the EOFs most relevant to the observed trend pattern are reasonably well represented. This gives confidence that our analysis has correctly identified a detectable change in Antarctic SIE. An important caveat is that the observation period is restricted to just three decades, and there is no way of verifying model performance at multidecadal and longer time scales from satellite data alone.

\section{Summary and discussion}

We have performed a detection analysis to determine whether observed Southern Ocean sea ice trends have a detectable signal that is outside the expected range of internal variability. This work differs from previous detection studies of Antarctic sea ice change in that we consider the heterogeneous spatial pattern of trends rather than simply the total sea ice cover. For the winter and spring seasons (JJA and SON), we cannot reject the null hypothesis that the observed trends are the result of internal variability alone. Some of the observed SON trend in the West Antarctic region may be an alias of multidecadal tropical Pacific variability, a result that merits more detailed physical analysis than is appropriate here. For the summer and autumn seasons (DJF and MAM), the models show a divergence in their response patterns, with some models showing detectable historical trends, both positive and negative, and other models showing barely any forced response. At a first pass, the identification of a detectable change in autumn but not in spring seems inconsistent with recent work showing that autumn trends are related to changes during the preceding spring (Holland 2014; Simpkins et al. 2013). A crucial point is that our method is designed to test whether there is a forced signal that is outside the range of "noise" (i.e., internal variability) and there may well be a forced response that, because of the shortness of the record or the magnitude of background noise, cannot be detected. With respect to the seasonality of our results, it is entirely plausible that there is a forced response in all seasons, which is separable from internal variability in some seasons but "swamped"' by noise during the highervariability winter months.

To address uncertainties in the models' responses to external forcing, we used an alternative detection approach to test whether the magnitude and pattern of observed SIE trends is unusual in the context of the model control runs. We find that, for the austral summer (DJF) and autumn (MAM), the observed trends are outside the range of simulated internal variability. This is largely due to the simultaneous increased SIE in the Ross Sea and decreased SIE in the Amundsen and Bellingshausen Seas; by contrast, the model control simulations show a positive covariance between these two sectors on multidecadal time scales. While there is a risk that this detectable signal is because of selection bias in the response pattern, examination of the leading EOFs suggests that this is probably not the case. Moreover, previous studies have demonstrated physical mechanisms that can force an inverse relationship between these sectors (Hobbs and Raphael 2010; Holland and Kwok 2012; Hosking et al. 2013; Li et al. 2014).

The individual ensemble members of the historical experiment are almost all within the range of internal variability (Fig. 7). However, taken as an ensemble the models clearly suggest an expected reduction in sea cover in all sectors over the period of analysis. This significant difference between forced historical simulations and observations has important implications for the current understanding of changes in Southern Ocean, because sea ice variability is due to both atmosphere and ocean processes and is an important benchmark of regional model validity. Our results bring into question the forced models' ability to consistently reproduce sea ice changes over the late twentieth century and by implication must also raise doubts about projections of Antarctic changes under future climate forcing scenarios. The recent IPCC Fifth Assessment Report assigns a low confidence to our scientific understanding of the observed changes in Antarctic sea ice, mainly because of the competing explanations (Bindoff et al. 2014) and a low confidence to Antarctic sea ice projections over the next century (Collins et al. 2014). We argue that, in light of the model deficiencies in the 
forced simulations shown by our results, there is in fact a very low confidence in our understanding of current and future Antarctic sea ice changes (where we use the terms "low confidence" and "very low confidence" as per the IPCC definitions).

Compared to these results for the Antarctic, the observed decline in Arctic sea ice cover is relatively well simulated by coupled models (Stroeve et al. 2012); the fact that the same coupled models perform much better in the Arctic than in the Antarctic suggests that the processes that are either deficient or missing from the coupled models' representation of sea ice are unique to the Antarctic climate system. A number of processes fit this description. The atmosphere (Hobbs and Raphael 2010; Holland and Kwok 2012; Raphael 2007) and ocean feedbacks between mixed layer temperature and salinity (Close and Goosse 2013; Zhang 2007) and increased freshwater flux from ice sheet melt (Bintanja et al. 2013; Swart and Fyfe 2013) have all been suggested as potential drivers of Antarctic sea ice changes. Sea ice response to atmospheric forcing is much more regional in the Antarctic compared to the Arctic (Hobbs and Raphael 2010; Holland and Kwok 2012; Raphael 2007), and atmospheric changes due to ozone depletion may be particularly important for the Ross Sea ice increases (Turner et al. 2009), although more recent studies indicate that ozone depletion alone would lead to a decrease in SIE (Bitz and Polvani 2012; Sigmond and Fyfe 2010). Freshwater flux from the West Antarctic Ice Sheet enters the ice-covered regions of the Southern Ocean, whereas Greenland meltwater largely enters the North Atlantic rather than the Arctic Ocean (Bamber et al. 2012). Since the CMIP5 models do not include the glaciological processes driving these changes, this freshwater input is unrepresented. Even the very processes by which sea ice is formed are more complex in the Southern Ocean than in the Arctic (Kimura and Wakatsuchi 2011; Maksym et al. 2012). Any or all of these effects could be instrumental in understanding the observed changes in Antarctic sea ice cover and in how they may be better represented in the future climate models. From this work and for the competing range of physical explanations listed above, we conclude that in general the global coupled models do not adequately represent the forced response of the Antarctic climate system.

The problem is complicated by the relatively short period of satellite observations, which is barely long enough to characterize multidecadal variability. An extended data record would allow much clearer separation of long-term change from internal variability, and we believe it should be considered a priority for the sea ice community. Meier et al. (2013b) used images from the Nimbus-1 satellite to estimate Antarctic sea ice extent in
September 1964 and, although sparse, historical records may offer the chance to extend the satellite record further back than the passive microwave era. For long-term change detection, however, there is a considerable challenge in understanding how best to compare visible radiation estimates of ice edge location with SIE derived from passive microwave ice concentrations. Another possible solution is the use of ice core records, from which sea salt and methane sulfonic acid can be used as proxies of sea ice cover (Abram et al. 2013). In particular, methane sulfonic acid concentrations from the Law Dome ice core have been shown to give a reliable estimate of regional sea ice cover on interannual time scales (Curran et al. 2003), and ice core records exist that could be proxies for other sea ice sectors, including the Ross, Amundsen, and Bellingshausen Seas, offering the potential for a centuryscale analysis of regional Antarctic ice cover.

In summary, unlike earlier work, we formally show that observed summer and autumn trends in Southern Ocean sea ice cover are outside the range of internal variability simulated by global coupled climate models. The coupled model sea ice response to realistic twentiethcentury external forcings is significantly different from both the observed trends and simulated internal variability, and discrepancies between the models and observations cannot be explained by internal variability alone. We conclude that in general the global coupled models do not adequately represent the forced response of the Antarctic climate system.

Acknowledgments. The authors wish to thank Paola Petrelli for help in accessing and managing the model data and Claudia Tebaldi, David Karoly, Gabi Hegerl, Ian Eisenman, and two anonymous reviewers for helpful comments during preparation of this manuscript. We acknowledge the use of the NCAR Command Language (NCL; doi:10.5065/D6WD3XH5) for data analysis and visualization. We further acknowledge the World Climate Research Programme's Working Group on Coupled Modelling, which is responsible for CMIP, and we thank the climate modelling groups (listed in Table 1 of this paper) for producing and making available their model output.

\section{REFERENCES}

Abram, N. J., E. W. Wolff, and M. A. J. Curran, 2013: A review of sea ice proxy information from polar ice cores. Quat. Sci. Rev., 79, 168-183, doi:10.1016/j.quascirev.2013.01.011.

Allen, M. R., and S. F. B. Tett, 1999: Checking for model consistency in optimal fingerprinting. Climate Dyn., 15, 419-434, doi:10.1007/s003820050291.

Arora, V. K., and Coauthors, 2011: Carbon emission limits required to satisfy future representative concentration pathways 
of greenhouse gases. Geophys. Res. Lett., 38, L05805, doi:10.1029/ 2010GL046270.

Bamber, J., M. van den Broeke, J. Ettema, J. Lenaerts, and E. Rignot, 2012: Recent large increases in freshwater fluxes from Greenland into the North Atlantic. Geophys. Res. Lett., 39, L19501, doi:10.1029/2012GL052552.

Bentsen, M., and Coauthors, 2012: The Norwegian Earth System Model, NorESM1-M-Part 1: Description and basic evaluation. Geosci. Model Dev. Discuss., 5, 2843-2931, doi:10.5194/ gmdd-5-2843-2012.

Bi, D., and Coauthors, 2013: The ACCESS coupled model: Description, control climate and evaluation. Aust. Meteor. Oceanogr. J., 63, 41-64.

Bindoff, N. L., and Coauthors, 2014: Detection and attribution of climate change: From global to regional. Climate Change 2013: The Physical Science Basis, T. D. Stocker et al., Eds., Cambridge University Press, 967-952.

Bintanja, R., G. J. van Oldenborgh, S. S. Drijfhout, B. Wouters, and C. A. Katsman, 2013: Important role for ocean warming and increased ice-shelf melt in Antarctic sea-ice expansion. Nat. Geosci., 6, 376-379, doi:10.1038/ngeo1767.

Bitz, C. M., and L. M. Polvani, 2012: Antarctic climate response to stratospheric ozone depletion in a fine resolution ocean climate model. Geophys. Res. Lett., 39, L20705, doi:10.1029/ 2012GL053393.

Cavalieri, D. J., C. L. Parkinson, P. Gloersen, J. C. Comiso, and H. J. Zwally, 1999: Deriving long-term time series of sea ice cover from satellite passive-microwave multisensor data sets. J. Geophys. Res., 104, 15 803-15 814, doi:10.1029/1999JC900081.

Close, S. E., and H. Goosse, 2013: Entrainment-driven modulation of Southern Ocean mixed layer properties and sea ice variability in CMIP5 models. J. Geophys. Res. Oceans, 118, 28112827, doi:10.1002/jgrc.20226.

Collins, M., and Coauthors, 2014: Long-term climate change: Projections, commitments and irreversibility. Climate Change 2013: The Physical Science Basis, T. F. Stocker et al., Eds., Cambridge University Press, 1029-1136.

Curran, M. A. J., T. D. van Ommen, V. I. Morgan, K. L. Phillips, and A. S. Palmer, 2003: Ice core evidence for Antarctic sea ice decline since the 1950s. Science, 302, 1203-1206, doi:10.1126/ science. 1087888 .

Ding, H., R. J. Greatbatch, and G. Gollan, 2014: Tropical influence independent of ENSO on the austral summer Southern Annular Mode. Geophys. Res. Lett., 41, 3643-3648, doi:10.1002/ 2014 GL059987.

Ding, Q. H., E. J. Steig, D. S. Battisti, and M. Kuttel, 2011: Winter warming in West Antarctica caused by central tropical Pacific warming. Nat. Geosci., 4, 398-403, doi:10.1038/ngeo1129.

Eisenman, I., W. N. Meier, and J. R. Norris, 2014: A spurious jump in the satellite record: Has Antarctic sea ice expansion been overestimated? Cryosphere, 8, 1289-1296, doi:10.5194/ tc-8-1289-2014.

Enfield, D. B., A. M. Mestas-Nunez, and P. J. Trimble, 2001: The Atlantic multidecadal oscillation and its relation to rainfall and river flows in the continental U.S. Geophys. Res. Lett., 28, 2077-2080, doi:10.1029/2000GL012745.

England, M. H., and Coauthors, 2014: Recent intensification of wind-driven circulation in the Pacific and the ongoing warming hiatus. Nat. Climate Change, 4, 222-227, doi:10.1038/nclimate2106.

Fan, T., C. Deser, and D. P. Schneider, 2014: Recent Antarctic sea ice trends in the context of Southern Ocean surface climate variations since 1950. Geophys. Res. Lett., 41, 2419-2426, doi:10.1002/2014GL059239.
Gent, P. R., and Coauthors, 2011: The Community Climate System Model version 4. J. Climate, 24, 4973-4991, doi:10.1175/ 2011JCLI4083.1.

Griffies, S. M., and Coauthors, 2011: The GFDL CM3 Coupled Climate Model: Characteristics of the ocean and sea ice simulations. J. Climate, 24, 3520-3544, doi:10.1175/2011JCLI3964.1.

Hobbs, W. R., and M. N. Raphael, 2010: The Pacific zonal asymmetry and its influence on Southern Hemisphere sea ice variability. Antarct. Sci., 22, 559-571, doi:10.1017/S0954102010000283.

Holland, P. R., 2014: The seasonality of Antarctic sea ice trends. Geophys. Res. Lett., 41, 4230-4237, doi:10.1002/2014GL060172. , and R. Kwok, 2012: Wind-driven trends in Antarctic sea-ice drift. Nat. Geosci., 5, 872-875, doi:10.1038/ngeo1627.

Hosking, J. S., A. Orr, G. J. Marshall, J. Turner, and T. Phillips, 2013: The influence of the Amundsen-Bellingshausen Seas low on the climate of West Antarctica and its representation in coupled climate model simulations. J. Climate, 26, 6633-6648, doi:10.1175/JCLI-D-12-00813.1.

Jin, D., and B. P. Kirtman, 2010: How the annual cycle affects the extratropical response to ENSO. J. Geophys. Res., 115, D06102, doi:10.1029/2009JD012660.

Jungclaus, J. H., and Coauthors, 2013: Characteristics of the ocean simulations in the Max Planck Institute Ocean Model (MPIOM), the ocean component of the MPI-Earth system model. J. Adv. Model Earth. Syst., 5, 422-446, doi:10.1002/jame.20023.

Kimura, N., and M. Wakatsuchi, 2011: Large-scale processes governing the seasonal variability of the Antarctic sea ice. Tellus, 63, 828-840, doi:10.1111/J.1600-0870.2011.00526.X.

Knutti, R., D. Masson, and A. Gettelman, 2013: Climate model genealogy: Generation CMIP5 and how we got there. Geophys. Res. Lett., 40, 1194-1199, doi:10.1002/grl.50256.

Li, L., and Coauthors, 2013: The Flexible Global OceanAtmosphere-Land System Model, Grid-point Version 2: FGOALS-g2. Adv. Atmos. Sci., 30, 543-560, doi:10.1007/ s00376-012-2140-6.

Li, X., D. M. Holland, E. P. Gerber, and C. Yoo, 2014: Impacts of the north and tropical Atlantic Ocean on the Antarctic Peninsula and sea ice. Nature, 505, 538-542, doi:10.1038/ nature12945.

Mahlstein, I., P. R. Gent, and S. Solomon, 2013: Historical Antarctic mean sea ice area, sea ice trends, and winds in CMIP5 simulations. J. Geophys. Res. Atmos., 118, 5105-5110, doi:10.1002/jgrd.50443.

Maksym, T., S. E. Stammerjohn, S. Ackley, and R. Massom, 2012: Antarctic sea ice-A polar opposite? Oceanography, 25, 140 151, doi:10.5670/oceanog.2012.88.

Mantua, N. J., S. R. Hare, Y. Zhang, J. M. Wallace, and R. C. Francis, 1997: A Pacific interdecadal climate oscillation with impacts on salmon production. Bull. Amer. Meteor. Soc., 78, 1069-1079, doi:10.1175/1520-0477(1997)078<1069: APICOW $>2.0 . \mathrm{CO} ; 2$.

Martin, G. M., and Coauthors, 2011: The HadGEM2 family of Met Office Unified Model climate configurations. Geosci. Model Dev., 4, 723-757, doi:10.5194/gmd-4-723-2011.

Meier, W. N., F. Fetterer, M. Savoie, S. Mallory, R. Duerr, and J. Stroeve, 2013a: NOAA/NSIDC climate data record of passive microwave sea ice concentration, version 2. National Snow and Ice Data Center, Boulder, CO. [Available online at http://nsidc. org/data/docs/noaa/g02202_ice_conc_cdr/.]

, D. Gallaher, and G. G. Campbell, 2013b: New estimates of Arctic and Antarctic sea ice extent during September 1964 from recovered Nimbus I satellite imagery. Cryosphere, 7, 699-705, doi:10.5194/tc-7-699-2013. 
Mignot, J., and S. Bony, 2013: Presentation and analysis of the IPSL and CNRM climate models used in CMIP5. Climate Dyn., 40, 2089-2089, doi:10.1007/s00382-013-1720-1.

Min, S. K., X. B. Zhang, F. W. Zwiers, and T. Agnew, 2008: Human influence on Arctic sea ice detectable from early 1990s onwards. Geophys. Res. Lett., 35, L21701, doi:10.1029/2008GL035725.

Neale, R. B., and Coauthors, 2010: Description of the NCAR Community Atmosphere Model (CAM5.0). NCAR Tech. Note NCAR/TN-486+STR, 268 pp.

North, G. R., T. L. Bell, R. F. Cahalan, and F. J. Moeng, 1982: Sampling errors in the estimation of empirical orthogonal functions. Mon. Wea. Rev., 110, 699-706, doi:10.1175/ 1520-0493(1982)110<0699:SEITEO > 2.0.CO;2.

O'Kane, T. J., R. J. Matear, M. A. Chamberlain, J. S. Risbey, B. M. Sloyan, and I. Horenko, 2013: Decadal variability in an OGCM Southern Ocean: Intrinsic modes, forced modes and metastable states. Ocean Modell., 69, 1-21, doi:10.1016/ j.ocemod.2013.04.009.

Okumura, Y. M., D. Schneider, C. Deser, and R. Wilson, 2012: Decadal-interdecadal climate variability over Antarctica and linkages to the tropics: Analysis of ice core, instrumental, and tropical proxy data. J. Climate, 25, 7421-7441, doi:10.1175/ JCLI-D-12-00050.1.

Parkinson, C. L., and D. J. Cavalieri, 2012: Antarctic sea ice variability and trends, 1979-2010. Cryosphere, 6, 871-880, doi:10.5194/ tc-6-871-2012.

Polvani, L. M., and K. L. Smith, 2013: Can natural variability explain observed Antarctic sea ice trends? New modeling evidence from CMIP5. Geophys. Res. Lett., 40, 3195-3199, doi:10.1002/grl.50578.

Raphael, M. N., 2007: The influence of atmospheric zonal wave three on Antarctic sea ice variability. J. Geophys. Res., 112, D12112, doi:10.1029/2006JD007852.

—_ and W. Hobbs, 2014: The influence of the large-scale atmospheric circulation on Antarctic sea ice during ice advance and retreat seasons. Geophys. Res. Lett., 41, 5037-5045, doi:10.1002/ 2014GL060365.

Ribes, A., S. Planton, and L. Terray, 2013: Application of regularised optimal fingerprinting to attribution. Part I: Method, properties and idealised analysis. Climate Dyn., 41, 2817-2836, doi:10.1007/s00382-013-1735-7.

Rotstayn, L. D., S. J. Jeffrey, M. A. Collier, S. M. Dravitzki, A. C. Hirst, J. I. Syktus, and K. K. Wong, 2012: Aerosol- and greenhouse gas-induced changes in summer rainfall and circulation in the Australasian region: A study using single-forcing climate simulations. Atmos. Chem. Phys., 12, 6377-6404, doi:10.5194/acp-12-6377-2012.

Schmidt, G. A., and Coauthors, 2014: Configuration and assessment of the GISS ModelE2 contributions to the CMIP5 archive. J. Adv. Model Earth Syst., 6, 141-184, doi:10.1002/2013ms000265.

Schneider, D. P., C. Deser, and Y. Okumura, 2012: An assessment and interpretation of the observed warming of West Antarctica in the austral spring. Climate Dyn., 38, 323-347, doi:10.1007/ s00382-010-0985-x.

Sigmond, M., and J. C. Fyfe, 2010: Has the ozone hole contributed to increased Antarctic sea ice extent? Geophys. Res. Lett., 37, L18502, doi:10.1029/2010GL044301.

Simpkins, G. R., L. M. Ciasto, and M. H. England, 2013: Observed variations in multidecadal Antarctic sea ice trends during 19792012. Geophys. Res. Lett., 40, 3643-3648, doi:10.1002/grl.50715.
—, S. McGregor, A. S. Taschetto, L. M. Ciasto, and M. H. England, 2014: Tropical connections to climatic change in the extratropical Southern Hemisphere: The role of Atlantic SST trends. J. Climate, 27, 4923-4936, doi:10.1175/JCLI-D-13-00615.1.

Stammerjohn, S. E., D. G. Martinson, R. C. Smith, X. Yuan, and D. Rind, 2008: Trends in Antarctic annual sea ice retreat and advance and their relation to El Niño-Southern Oscillation and southern annular mode variability. J. Geophys. Res., 113, C03S90, doi:10.1029/2007JC004269.

Stroeve, J. C., V. Kattsov, A. Barrett, M. Serreze, T. Pavlova, M. Holland, and W. N. Meier, 2012: Trends in Arctic sea ice extent from CMIP5, CMIP3 and observations. Geophys. Res. Lett., 39, L16502, doi:10.1029/2012GL052676.

Swart, N. C., and J. C. Fyfe, 2013: The influence of recent Antarctic ice sheet retreat on simulated sea ice area trends. Geophys. Res. Lett., 40, 4328-4332, doi:10.1002/grl.50820.

Taylor, K. E., R. J. Stouffer, and G. A. Meehl, 2012: An overview of CMIP5 and the experiment design. Bull. Amer. Meteor. Soc., 93, 485-498, doi:10.1175/BAMS-D-11-00094.1.

Turner, J., and Coauthors, 2009: Non-annular atmospheric circulation change induced by stratospheric ozone depletion and its role in the recent increase of Antarctic sea ice extent. Geophys. Res. Lett., 36, L08502, doi:10.1029/2009GL037524.

_ - T. J. Bracegirdle, T. Phillips, G. J. Marshall, and J. S. Hosking, 2013: An initial assessment of Antarctic sea ice extent in the CMIP5 models. J. Climate, 26, 1473-1484, doi:10.1175/ JCLI-D-12-00068.1.

Voldoire, A., and Coauthors, 2012: The CNRM-CM5.1 global climate model: Description and basic evaluation. Climate Dyn., 40, 2091-2121, doi:10.1007/s00382-011-1259-y.

Watanabe, M., and Coauthors, 2010: Improved climate simulation by MIROC5: Mean states, variability, and climate sensitivity. J. Climate, 23, 6312-6335, doi:10.1175/2010JCLI3679.1.

Watanabe, S., and Coauthors, 2011: MIROC-ESM 2010: Model description and basic results of CMIP5-20c3m experiments. Geosci. Model Dev., 4, 845-872, doi:10.5194/gmd-4-845-2011.

Xin, X.-G., T.-W. Wu, and J. Zhang, 2013: Introduction of CMIP5 experiments carried out with the climate system models of Beijing Climate Center. Adv. Climate Change Res., 4, 41-49, doi:10.3724/SP.J.1248.2013.00041.

Yuan, X. J., 2004: ENSO-related impacts on Antarctic sea ice: A synthesis of phenomenon and mechanisms. Antarct. Sci., 16, 415-425, doi:10.1017/S0954102004002238.

— predictability. Geophys. Res. Lett., 28, 3609-3612, doi:10.1029/ 2001 GL012969.

Yukimoto, S., and Coauthors, 2012: A new global climate model of the Meteorological Research Institute: MRI-CGCM3Model description and basic performance. J. Meteor. Soc. Japan, 90A, 23-64, doi:10.2151/jmsj.2012-A02.

Zhang, J. L., 2007: Increasing Antarctic sea ice under warming atmospheric and oceanic conditions. J. Climate, 20, 2515-2529, doi:10.1175/JCLI4136.1.

Zunz, V., H. Goosse, and F. Massonnet, 2013: How does internal variability influence the ability of CMIP5 models to reproduce the recent trend in Southern Ocean sea ice extent? Cryosphere, 7, 451-468, doi:10.5194/tc-7-451-2013.

Zwiers, F. W., and H. von Storch, 1995: Taking serial-correlation into account in tests of the mean. J. Climate, 8, 336-351, doi:10.1175/1520-0442(1995)008<0336:TSCIAI >2.0.CO;2. 